University of South Florida

DIGITAL COMMONS

Digital Commons @ University of

@ UNIVERSITY OF SOUTH FLORIDA

South Florida

Marine Science Faculty Publications

College of Marine Science

3-16-2007

\title{
Euphotic Zone Depth: Its Derivation and Implication to Ocean- Color Remote Sensing
}

\author{
ZhongPing Lee \\ Stennis Space Center \\ Alan Weidemann \\ Stennis Space Center \\ John Kindle \\ Stennis Space Center \\ Robert Arnone \\ Stennis Space Center \\ Kendall L. Carder \\ University of South Florida, kcarder@marine.usf.edu
}

See next page for additional authors

Follow this and additional works at: https://digitalcommons.usf.edu/msc_facpub

Part of the Marine Biology Commons

\section{Scholar Commons Citation}

Lee, ZhongPing; Weidemann, Alan; Kindle, John; Arnone, Robert; Carder, Kendall L.; and Davis, Curtiss, "Euphotic Zone Depth: Its Derivation and Implication to Ocean-Color Remote Sensing" (2007). Marine Science Faculty Publications. 11.

https://digitalcommons.usf.edu/msc_facpub/11

This Article is brought to you for free and open access by the College of Marine Science at Digital Commons @ University of South Florida. It has been accepted for inclusion in Marine Science Faculty Publications by an authorized administrator of Digital Commons @ University of South Florida. For more information, please contact digitalcommons@usf.edu. 


\section{Authors}

ZhongPing Lee, Alan Weidemann, John Kindle, Robert Arnone, Kendall L. Carder, and Curtiss Davis 


\title{
Euphotic zone depth: Its derivation and implication to ocean-color remote sensing
}

\author{
ZhongPing Lee, ${ }^{1}$ Alan Weidemann, ${ }^{1}$ John Kindle, ${ }^{1}$ Robert Arnone, ${ }^{1}$ Kendall L. Carder, ${ }^{2}$ \\ and Curtiss Davis ${ }^{3}$ \\ Received 6 July 2006; revised 12 October 2006; accepted 1 November 2006; published 16 March 2007.
}

[1] Euphotic zone depth, $z_{1 \%}$, reflects the depth where photosynthetic available radiation (PAR) is $1 \%$ of its surface value. The value of $z_{1 \%}$ is a measure of water clarity, which is an important parameter regarding ecosystems. Based on the Case-1 water assumption, $z_{1 \%}$ can be estimated empirically from the remotely derived concentration of chlorophyll-a ([Chl]), commonly retrieved by employing band ratios of remote sensing reflectance $\left(R_{\mathrm{rs}}\right)$. Recently, a model based on water's inherent optical properties (IOPs) has been developed to describe the vertical attenuation of visible solar radiation. Since IOPs can be nearanalytically calculated from $R_{\mathrm{rs}}$, so too can $z_{1 \%}$. In this study, for measurements made over three different regions and at different seasons $\left(z_{1 \%}\right.$ were in a range of $4.3-82.0 \mathrm{~m}$ with [Chl] ranging from 0.07 to $\left.49.4 \mathrm{mg} / \mathrm{m}^{3}\right), z_{1 \%}$ calculated from $R_{\mathrm{rs}}$ was compared with $z_{1 \%}$ from in situ measured PAR profiles. It is found that the $z_{1 \%}$ values calculated via $R_{\mathrm{rs}}$-derived IOPs are, on average, within $\sim 14 \%$ of the measured values, and similar results were obtained for depths of $10 \%$ and $50 \%$ of surface PAR. In comparison, however, the error was $\sim 33 \%$ when $z_{1 \%}$ is calculated via $R_{\mathrm{rs}}$-derived [Chl]. Further, the importance of deriving euphotic zone depth from satellite ocean-color remote sensing is discussed.

Citation: Lee, Z., A. Weidemann, J. Kindle, R. Arnone, K. L. Carder, and C. Davis (2007), Euphotic zone depth: Its derivation and implication to ocean-color remote sensing, J. Geophys. Res., 112, C03009, doi:10.1029/2006JC003802.

\section{Introduction}

[2] Euphotic zone depth, $z_{1 \%}$, reflects the depth where only $1 \%$ of the surface photosynthetic available radiation (PAR) remains [Kirk, 1994]. $z_{1 \%}$ is a measure of water clarity, which is not only a quality index of an ecosystem but also an important property for primary production [Behrenfeld and Falkowski, 1997; Platt and Sathyendranath, 1988] and heat transfer [Chang and Dickey, 2004; Kara et al., 2005; Sathyendranath et al., 1991] in the upper water column. Based on Case-1 water assumptions [Morel, 1988; Morel and Prieur, 1977], $z_{1 \%}$ can be estimated from remotely derived concentration of chlorophyll-a or total pigments, with either a spectrally integrated form [Morel, 1988] or a spectrally resolved formalism [Prieur and Sathyendranath, 1981; Sathyendranath et al., 1989a].

[3] Case-1 waters are those whose inherent optical properties [Preisendorfer, 1976] can be adequately described by phytoplankton (represented by chlorophyll concentration) [Gordon and Morel, 1983; IOCCG, 2000; Morel, 1988; Morel and Prieur, 1977]. Case-1 waters thus require the optical properties of other optically active constituents (such

\footnotetext{
${ }^{1}$ Naval Research Laboratory, Stennis Space Center, Mississippi, USA. ${ }^{2}$ College of Marine Science, University of South Florida, St. Petersburg, Florida, USA.

${ }^{3}$ College of Oceanic and Atmospheric Sciences, Oregon State University, Corvallis, Oregon, USA.
}

Copyright 2007 by the American Geophysical Union. 0148-0227/07/2006JC003802 as Colored Dissolved Organic Matter and suspended particles) closely follow the optical properties of phytoplankton [Morel, 1988; Morel and Maritorena, 2001]. Because the definition of Case-1 water is not based on the geographical location, nor based on the value of chlorophyll, it is difficult to know a priori if a water body fits the Case-1 definition when it is measured by a remote sensor. Frequently open ocean waters are assumed as Case-1, but recent studies [Lee and Hu, 2006; Mobley et al., 2004] have shown that this could be problematic, as in general water's optical properties are not determined by phytoplankton alone [Sathyendranath et al., 1989b].

[4] To incorporate the dependence of subsurface light field on other water constituents (such as CDOM), Liu et al. [2002] developed a numerical model (via look-up-table) that uses information about chlorophyll concentration, CDOM absorption and particle scattering coefficient as inputs to describe the vertical distribution of downwelling irradiance. This approach, similar as those based on Case-1 assumption [Morel and Antoine, 1994; Ohlmann and Siegel, 2000; Sathyendranath et al., 1989a], however, still requires accurate information about chlorophyll concentration when applied to ocean-color remote sensing. Liu et al. [2006] are successful using this approach for waters of the West Florida Shelf.

[5] In another empirical approach, Mueller and Lange [1989] developed relationships to calculate $z_{1 \%}$ directly from the diffuse attenuation coefficient at $490 \mathrm{~nm}$. The associated empirical constants, however, were developed 
for a specific region and specific temporal ranges [Mueller and Lange, 1989], it is then difficult to apply the empirical relationships to the global oceans at different seasons.

[6] Recently, based on the principle that the vertical variation of subsurface light field is determined by inherent optical properties (IOPs), Lee et al. [2005b] developed an analytical model to describe the vertical attenuation of downwelling vector irradiance in the visible domain $\left(E_{\mathrm{VIS}}\right.$, $350-700 \mathrm{~nm})$. In this IOP-centered approach, the vertical attenuation coefficient of $E_{\mathrm{VIS}}\left(K_{\mathrm{VIS}}(z)\right)$ is modeled as an analytical function of water's absorption and backscattering coefficients. For vertical distributions of $E_{\mathrm{VIS}}(z)$ ranging from 0.1 to $100 \%$ of the surface value, the modeled $E_{\mathrm{VIS}}(z)$ is accurate to within $\sim 6 \%$ of the actual value [Lee et al., 2005b], for a data set simulated using Hydrolight [Mobley, 1995]. Since the vertical distribution of $E_{\mathrm{VIS}}(z)$ is nearly identical to that of PAR(z) [Lee et al., 2005b; Morel and Gentili, 2004], $z_{1 \%}$ can be easily calculated when IOPs (the absorption and backscattering coefficients at $490 \mathrm{~nm}$, in particular) are known, either from in situ measurements or from remote sensing of ocean color.

[7] Regardless of whether one uses the Case-1 approaches or the recent IOP-centered approach, there has been no test or validation of $z_{1 \%}$ algorithms with a broadrange in situ data. On the other hand, global or basin scale estimation of $z_{1 \%}$ from ocean color has been incorporated into studies of new production [Behrenfeld et al., 2005] and the Sverdrup hypothesis [Siegel et al., 2002]. To ensure reliable products for these biogeochemical studies, it is desirable to know the accuracy of remotely derived $z_{1 \%}$ for broad range of waters.

[8] In this study, for measurements made in the Arabian Sea, the Monterey Bay and the Gulf of Mexico that covered both oceanic and coastal waters and measured at different seasons, $z_{1 \%}$ (and $z_{10 \%}, z_{50 \%}$ ) are calculated from spectral remote-sensing reflectance using both the Case-1 and IOPcentered approaches. With an emphasis on computational efficiency, only spectrally integrated approaches are studied here. The calculated $z_{x \%}$ ( $x$ represents 1,10 , or 50 in this article) values are then compared with those from profiles of PAR measurements to evaluate the performance of the approaches. Further, we discussed the unique characteristics of property $z_{1 \%}\left(\right.$ and/or $\left.z_{10 \%}\right)$ and its importance in ocean color remote sensing.

\section{Data and Methods}

[9] Field measurements from three different regions are used for testing and evaluating the methods for deriving $z_{x \%}$ from $R_{\mathrm{rs}}$. These regions are: the Monterey Bay (data collected in September and October 1989), the Gulf of Mexico (April and June 1993), and the Arabian Sea (December 1994). These water environments include open-ocean oligotrophic waters (the Loop Current, and Arabian Sea), coastal high-productivity waters (the Monterey Bay, the West Florida Shelf), and turbid Mississippi River plume waters. The range of chlorophyll-a concentration measured was $\sim 0.07-49.4 \mathrm{mg} / \mathrm{m}^{3}$ with $z_{1 \%}$ ranging from $\sim 4.3$ to $82.0 \mathrm{~m}$. During these measurements the above-surface solar zenith angles $\left(\theta_{\mathrm{a}}\right)$ were between $8^{\circ}$ and $80^{\circ}\left(30 \%\right.$ of them with $\left.\theta_{\mathrm{a}}>50^{\circ}\right)$. For the conditions with the Sun covered by clouds, $\theta_{\mathrm{a}}$ is taken in our calculations as $45^{\circ}$ as in Sathyendranath et al. [1989a].

[10] There are 65 stations that include measurements of both remote-sensing reflectance and vertical profiles of PAR. Remote-sensing reflectance at wavelength $\lambda, R_{r s}(\lambda)$, was calculated from measurements made above the sea surface as described in Carder and Steward [1985], with upwelling radiance, downwelling irradiance, and downwelling sky radiance measured by a handheld spectroradiometer. The methodology of determining in situ $R_{r s}(\lambda)$ is described in detail in NASA protocols [Mueller et al., 2002a].

[11] Instantaneous PAR (400-700 nm) in the upper water column at time $t\left(P A R_{t}(z)\right)$ was measured by lowering a PAR sensor (Biospherical Instruments, Inc.) from surface to depth ( $z \mathrm{~m}$, positive downward). $z$ was measured by a pressure sensor, and was accurate to within $0.1 \mathrm{~m}$ with a fall rate of $1 \mathrm{~m}$ per second. During the deployment of the PAR sensor in the water column, a deck cell was operated to measure simultaneously the above-surface downwelling irradiance at time $t\left(E_{s}(490, t)\right)$, in order to correct for any variations of input solar light resulting from passing clouds. The vertical profile of PAR free of cloud effects is [Smith et al., 1984]

$$
\operatorname{PAR}(z)=\operatorname{PAR}_{t}(z) \frac{E_{S}(490 \mathrm{~nm}, 0)}{E_{S}(490 \mathrm{~nm}, t)} .
$$

From these $P A R(z)$ values, the ratio of PAR at depth to surface PAR $(P A R(0))$ was calculated as

$$
r_{P A R}(z)=\frac{P A R(z)}{P A R(0)} .
$$

$z_{50 \%}, z_{10 \%}$ and $z_{1 \%}$ (corresponding to $r_{P A R}$ equals $0.5,0.1$ and 0.01 , respectively) were then determined from the vertical profile of $r_{P A R}(z)$. It is rare to have recorded depth with $r_{P A R}(z)$ exactly the desired ratio $(10.0 \%$, for example). The measured $z_{x \%}$ value is then an approximation by exponentially interpolating $r_{P A R}(z)$ between $\sim 1.1 x \%$ and $0.9 x \%$. Because the depth interval reported for the vertical profiler is less than $1 \mathrm{~m}$, the maximum error in $z_{x \%}$ is less than $0.5 \mathrm{~m}$.

[12] For some earlier measurements (the 9 Monterey Bay stations in 1989 and 10 stations in the Gulf of Mexico in 1993), the PAR sensor was not sensitive enough to provide a reading when PAR is $1 \%$ of $P A R(0)$. For those stations, only $z_{10 \%}$ and $z_{50 \%}$ were directly obtained from $r_{P A R}(z)$ profiles.

[13] For the other stations where both $z_{10 \%}$ and $z_{1 \%}$ could be obtained from $r_{P A R}(z)$, it is found that a good linear relationship exists between $z_{10 \%}$ and $z_{1 \%}$ (see Figure 1). For $z_{1 \%}$ in the range of $4.3-64.4 \mathrm{~m}\left(z_{10 \%}\right.$ in the range of $2.1-$ $29.0 \mathrm{~m}$ ), by forcing the linear-regression line to pass through the origin, the following relation was obtained,

$$
z_{1 \%}=2.25 z_{10 \%}
$$

with a coefficient of determination of $0.99(n=43)$. In this regression analysis, the two measurements with $z_{1 \%}$ of $\sim 82.0 \mathrm{~m}$ (the black points in Figure 1) were excluded, simply because they were significantly beyond the general linear trend with too few points in that range to make a 


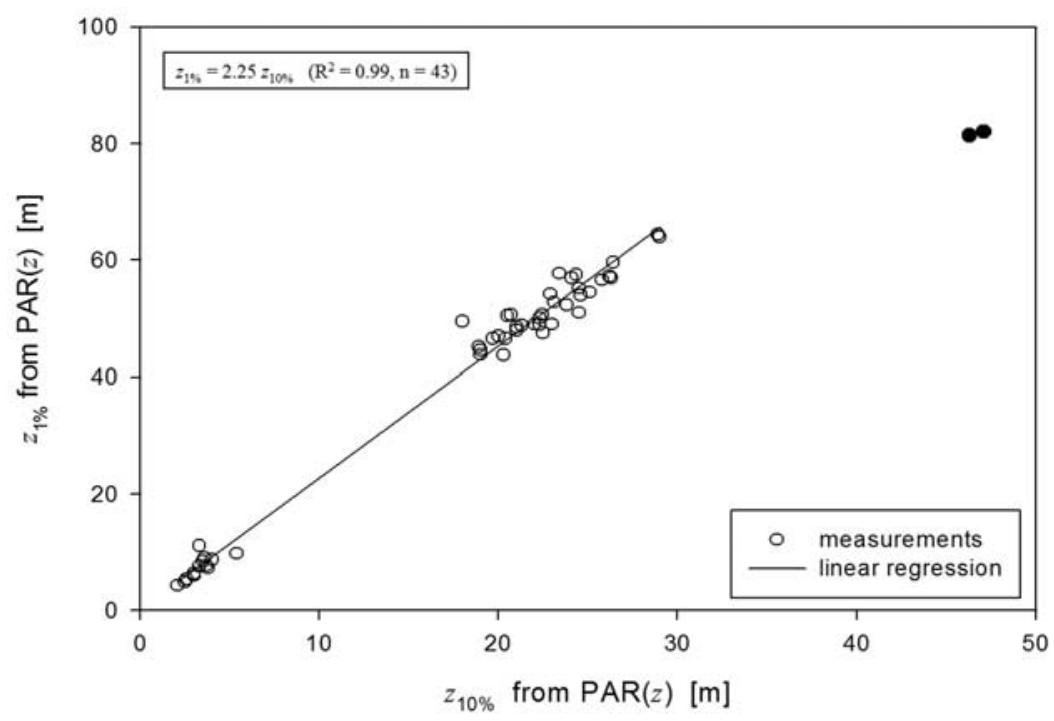

Figure 1. Relationship between $z_{1 \%}$ and $z_{10 \%}$ from in situ PAR profiles. The two black dots were excluded in the linear regression, and the range of $z_{10 \%}$ is $2.1-29.0 \mathrm{~m}$.

confident generalization. For the same ranges of $z_{1 \%}$ and $z_{10 \%}$, simulations using Hydrolight [Mobley, 1995] with different sun angles and IOPs indicate a nearly identical relationship as equation (3) (with a slope of 2.21). These results then suggest that equation (3) does represent a reliable relationship between $z_{1 \%}$ and $z_{10 \%}$, at least for $z_{10 \%}$ in this specific range of $\sim 2-30 \mathrm{~m}$. Therefore, for those stations where no $z_{1 \%}$ were obtainable from $r_{P A R}(z)$ and $z_{10 \%}$ was in the range of $2-30 \mathrm{~m}, z_{1 \%}$ values representing PAR profiles were derived by applying equation (3). In essence, in this study, equation (3) is only utilized for rangeconstrained interpolation, not for extrapolation.

[14] Usually, $z_{10 \%}$ is assumed to be half of $z_{1 \%}\left(z_{10 \%}\right.$ is called midpoint depth in Kirk [1994]). This is based on the assumption that the attenuation coefficient for PAR $\left(K_{\mathrm{PAR}}\right)$ does not change with depth. However, because PAR converges to wavelengths with less attenuation coefficients when PAR propagates from surface to deeper depths, $K_{\mathrm{PAR}}$ is always smaller at depth than at surface (the difference can be a factor of 2 or 3 ) even for a vertically homogeneous water environment [Lee et al., 2005b; Morel, 1988; Zaneveld et al., 1993], and thus $z_{10 \%}$ is shallower than half of $z_{1 \%}$.

\section{Derive $z_{1 \%}$ From $R_{\mathrm{rs}}$}

\subsection{IOP-Centered Approach}

[15] The vertical distribution of downwelling irradiance in the visible domain $\left(E_{\mathrm{VIS}}, 350-700 \mathrm{~nm}\right)$ is described as

$$
E_{V I S}(z)=E_{V I S}(0) e^{-K_{V I S}(z) z}
$$

$K_{\mathrm{VIS}}(z)$, the attenuation coefficient of $E_{\mathrm{VIS}}$, however, is no longer treated as independent of $z$ but a function of both $z$ and inherent optical properties [Lee et al., 2005b],

$$
K_{V I S}(z)=K_{1}+\frac{K_{2}}{(1+z)^{0.5}}
$$

with

$$
\left\{\begin{array}{c}
K_{1}=\left[\chi_{0}+\chi_{1}(a(490))^{0.5}+\chi_{2} b_{b}(490)\right]\left(1+\alpha_{0} \sin \left(\theta_{a}\right)\right), \\
K_{2}=\left[\zeta_{0}+\zeta_{1} a(490)+\zeta_{2} b_{b}(490)\right]\left(\alpha_{1}+\alpha_{2} \cos \left(\theta_{a}\right)\right),
\end{array}\right.
$$

where $a(490)$ and $b_{\mathrm{b}}(490)$ are water absorption and backscattering coefficients at $490 \mathrm{~nm}$, and $\chi_{0,1,2}, \varsigma_{0,1,2}$ and $\alpha_{0,1,2}$ are model constants derived from Hydrolight simulations [Lee et al., 2005b]. Given a sun angle and values of $a(490)$ and $b_{\mathrm{b}}(490), K_{\mathrm{VIS}}(z)$ can then be calculated for any depth.

[16] Defining the optical depth, $\tau_{E}$, for $E_{\mathrm{VIS}}$ as

$$
K_{V I S}(z) z=\tau_{E}
$$

then the depth where $E_{\mathrm{VIS}}(z)$ is $1 \%$ of $E_{\mathrm{VIS}}(0)$ is $-\ln (0.01)=$ $\tau_{E}=4.605$. Combining equations (5) and (7), after simple math manipulations, a cubic-polynomial equation with $z$ as the variable is obtained

$$
z^{3}+y_{1} z^{2}+y_{2} z+y_{3}=0
$$

with $y_{1-3}$ functions of $K_{1}, K_{2}$ and $\tau_{E}$,

$$
\left\{\begin{array}{c}
y_{1}=\frac{K_{1}^{2}-K_{2}^{2}-2 \tau_{E} K_{1}}{K_{1}^{2}}, \\
y_{2}=\frac{\tau_{E}^{2}-2 \tau_{E} K_{1}}{K_{1}^{2}}, \\
y_{3}=\frac{\tau_{E}^{2}}{K_{1}^{2}} .
\end{array}\right.
$$

Mathematically there are three solutions (one negative, two positives) that satisfy equation (8), but it is the smaller, positive, value that is consistent with radiative transfer theory. In this study, as examples to demonstrate this IOPcentered approach, $z$ for $\tau_{E}$ equals $4.605\left(E_{\mathrm{VIS}}(z) / E_{\mathrm{VIS}}(0)=\right.$ 
$1 \%), 2.303(10 \%)$, and $0.693(50 \%)$ are calculated for those measurements, respectively.

[17] Before the derivation of $z$ for different $\tau_{E}$, inherent optical properties $\left(a(490)\right.$ and $b_{\mathrm{b}}(490)$ in particular) were derived from $R_{\mathrm{rs}}$ using the quasi-analytical algorithm (QAA) [Lee et al., 2002]. QAA is an algorithm for deriving absorption and backscattering coefficients of optically deep waters from ocean-color remote sensing. Its concept and architecture are documented in detail in Lee et al. [2002]. Here a slightly updated version of QAA (v4) was applied, and the details of the updates are provided in Appendix A.

[18] It is necessary to point out that $E_{\mathrm{VIS}}$ in equation (4) represents downwelling vector irradiance in the range of $350-700 \mathrm{~nm}$, and is measured by energy $\left(\mathrm{W} / \mathrm{m}^{2}\right)$, whereas the PAR sensor measures both downwelling and upwelling scalar irradiance in the range of $400-700 \mathrm{~nm}$ and is measured by the amount of photons (quanta $/ \mathrm{m}^{2} / \mathrm{s}$ ). For the same wavelength range $(400-700 \mathrm{~nm})$, Hydrolight simulations [Morel and Gentili, 2004] indicate that $z_{1 \%}$ is about the same when it is measured either by $E_{\mathrm{VIS}}$ or by PAR (Table 2 of Morel and Gentili [2004]). Also, sensitivity tests with Hydrolight simulations indicate that the vertical profile of $E_{\mathrm{VIS}}$ is nearly identical to that of PAR, partially because upwelling irradiance is in the order of $\sim 5 \%$ of downwelling irradiance, and that the irradiance in the range of 350$400 \mathrm{~nm}$ is small. In general, the difference between $z_{x \%}$ measured by either $E_{\mathrm{VIS}}$ or PAR is small (less than $10 \%$ ). Therefore, $z_{x \%}$ calculated from equation (4) is considered equivalent and comparable to that determined from the vertical profiles of $\operatorname{PAR}(z)$.

\section{2. [Chl]-Centered Approach}

[19] Based on the Case-1 water assumption, and in a spectrally integrated form, $z_{1 \%}$ can be estimated from chlorophyll-a concentration ([Chl]) of the surface layer (A. Morel, personal communication, after the statistical analysis of the shape of [Chl] vertical profiles [Morel and Berthon, 1989]),

$$
z_{1 \%}=34.0([C h l])^{-0.39} .
$$

Because surface [Chl] can be calculated from $R_{\mathrm{rs}}(\lambda)$ by the operational OC4v4 algorithm [O'Reilly et al., 2000],

$$
[C h l]=10^{0.366-3.067 \rho+1.93 \rho^{2}+0.649 \rho^{3}-1.532 \rho^{4}},
$$

with

$$
\rho=\log \left(\frac{\max \left(R_{r s}(440,490,510)\right)}{R_{r s}(555)}\right),
$$

it is then quite straightforward to estimate $z_{1 \%}$ via this route.

\section{Results and Discussion}

[20] To evaluate and analyze the performance of deriving $z_{x \%}$ from ocean-color remote sensing, Figure 2 (2a for $r_{P A R}=0.5(50 \%), 2 \mathrm{~b}$ for $r_{P A R}=10 \%$, and $2 \mathrm{c}$ for $r_{P A R}=1 \%$ ) and Figure 3 present $R_{\mathrm{rs}}$-derived values $\left(z_{i}^{\text {der }}\right)$ versus those determined from $r_{P A R}(z)\left(z_{i}^{m e a}\right)$, and Table 1 summarizes their errors. Quantitatively, an averaged percentage error for all observations is calculated from

$$
\varepsilon=\frac{\sum_{i=1}^{n} \frac{k_{i}^{\text {der }}-z_{i}^{\text {mea }}}{\mid z_{i}^{\text {mea }}} \mid}{n} \times 100 \% .
$$

[21] Measurements at one station were excluded from these analyses because $z_{1 \%}$ from remote-sensing reflectance (no matter which method) is about four times the $z_{1 \%}$ from PAR profile. This one station is regarded as an outlier because of the significant difference between in-water and above-water determinations.

\subsection{IOP-Centered Approach}

[22] For this data set (64 stations) that covers both oceanic and coastal waters, the average percentage error $(\varepsilon)$ between modeled and measured property is $18.5 \%$ (with a maximum error of $70.9 \%$ ) for $z_{50 \%}$ (for a range of $0.6-$ $18.4 \mathrm{~m}$ from PAR measurements); while the errors are $13.8 \%$ (maximum error of $61.2 \%$ ) for $z_{10 \%}(2.1-47.1 \mathrm{~m})$, and $13.7 \%$ (maximum error of $63.5 \%$ ) for $z_{1 \%}$ (4.3 to $82.0 \mathrm{~m}$ ). The root-mean-square error in log scale (RMSE) is 0.079 for $z_{1 \%}$, significantly smaller than the RMSE $(0.329)$ of $R_{\mathrm{rs}}$-derived [Chl] (also see Figure 4).

[23] For $z_{50 \%}$, excluding the residual errors in the $K_{\mathrm{VIS}}$ model and the QAA algorithm, there are a few extra sources to contribute to its discrepancies. These extra sources include (1) PAR(z) attenuates sharply at surface [Paulson and Simpson, 1977; Zaneveld and Spinrad, 1980], making it harder to precisely determine $z_{50 \%}$ from the profile of $r_{P A R}(z)$; (2) surface layer suffers more influence from the wavy surface [Zaneveld et al., 2001], which can converge or diverge incoming solar radiation; and (3) variable shipperturbation to the near-surface sensor [Gordon, 1985].

[24] Additionally, larger error came from the two clearwater stations (the two with circles in Figure 2), where surface chlorophyll-a values were around $0.07 \mathrm{mg} / \mathrm{m}^{3}$. The two stations had similar [Chl] values and similar $R_{\mathrm{rs}}$ spectra, and nearly identical $z_{10 \%}$ and $z_{1 \%}$ depths from $\operatorname{PAR}(z)$ profiles (see Figures $2 \mathrm{~b}$ and $2 \mathrm{c}$ ); their $z_{50 \%}$ depths from $\operatorname{PAR}(z)$, however, differed by nearly $80 \%$. It is not clear yet what might have caused such big differences in the $z_{50 \%}$ from $\operatorname{PAR}(z)$ measurements. Excluding these two stations, the average error for $z_{50 \%}$ dropped to $16.8 \%$.

[25] Much better results are achieved for $z_{10 \%}$ (and $z_{1 \%}$ ), though, again, larger errors occurred at the two clearer-water stations (Figure $2 \mathrm{~b}$, in circle). Unlike $z_{50 \%}$, however, the $z_{10 \%}$ values from $\operatorname{PAR}(z)$ are about the same for these two stations. Overall, it appears that there is a trend of slight underestimation for $z_{10 \%}$ in the range of $10-30 \mathrm{~m}$ for this historical data set. High-quality measurements of both IOPs and $\operatorname{PAR}(z)$ profiles are required to isolate the error sources.

[26] For the entire range of $z_{1 \%}(4.3-82.0 \mathrm{~m})$ measured at different times and from different regions, the $R_{\mathrm{rs}}$ derived values clearly matched the $\operatorname{PAR}(z)$-determined values very well. Though many potential sources of error prevent exact agreement between the two independent data sets, the low average error ( $13.7 \%$ in linear scale, 0.079 in RMSE) for $z_{1 \%}$ indirectly validated the approach of deriving IOPs from $R_{\mathrm{rs}}$ and calculating $K_{\mathrm{VIS}}(z)$ from IOPs. It is even more 

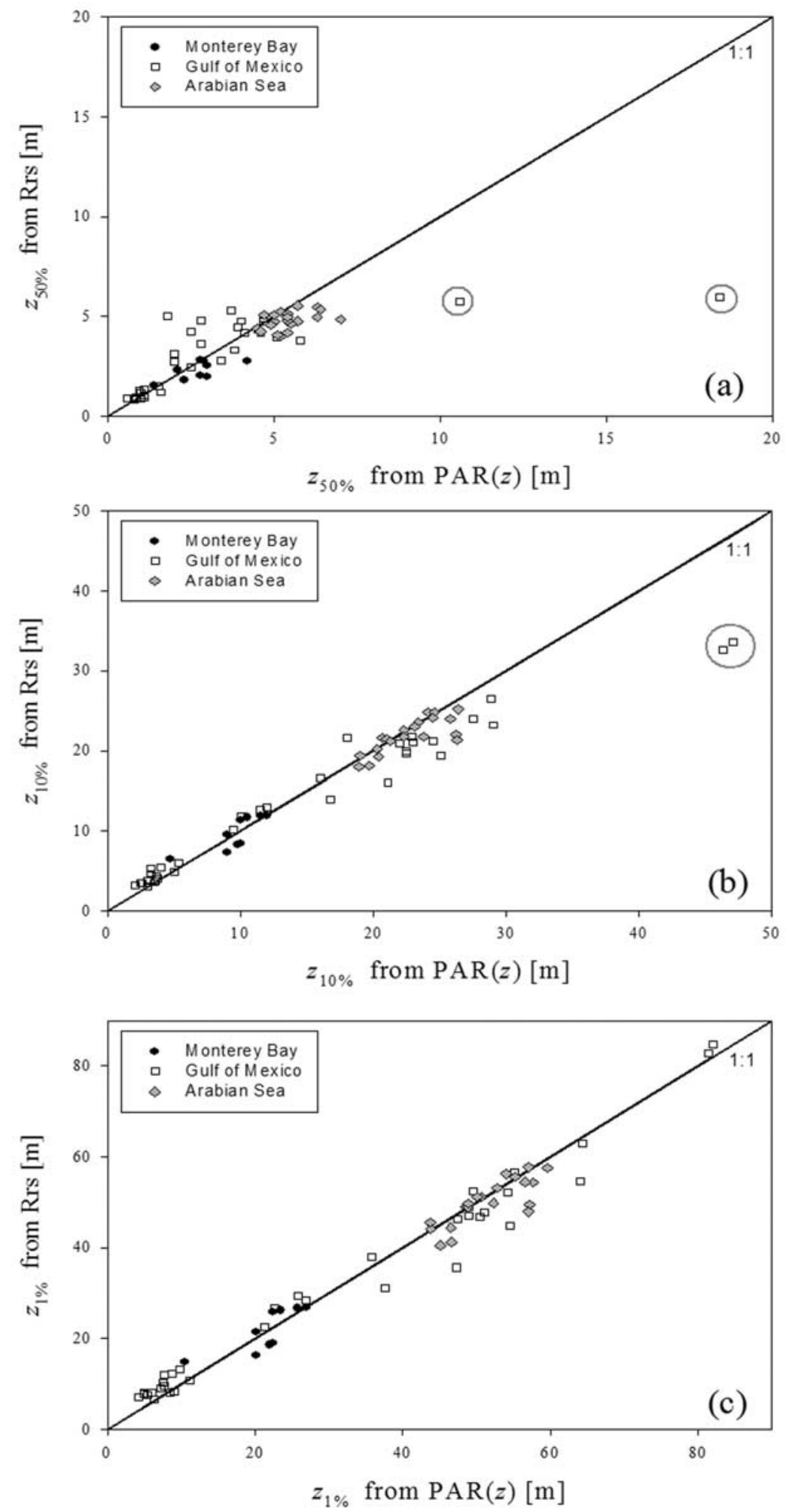

Figure 2. Comparison between $z_{x \%}$ from IOP-centered approach and $z_{x \%}$ from in situ PAR profile (a) for $z_{50 \%}$, (b) for $z_{10 \%}$, and (c) for $z_{1 \%}$. The two circled stations (Figure 2a) had nearly identical $z_{10 \%}$ (Figure 2b) and $z_{1 \%}$ (Figure 2c) values.

encouraging given that the measurements were not made in vertically homogeneous waters. If we use the vertical variation (within the euphotic zone) of the diffuse attenuation coefficient $\left[\right.$ Kirk, 1994] at $440 \mathrm{~nm}\left(K_{\mathrm{d}}(440)\right)$ as a proxy to represent the non-homogeneity of optical properties in the upper water column, the average coefficient of variation is $17 \%$ (maximum is $51 \%$ ) for this data set. If the variation is determined by chlorophyll fluorescence profile, the aver- 


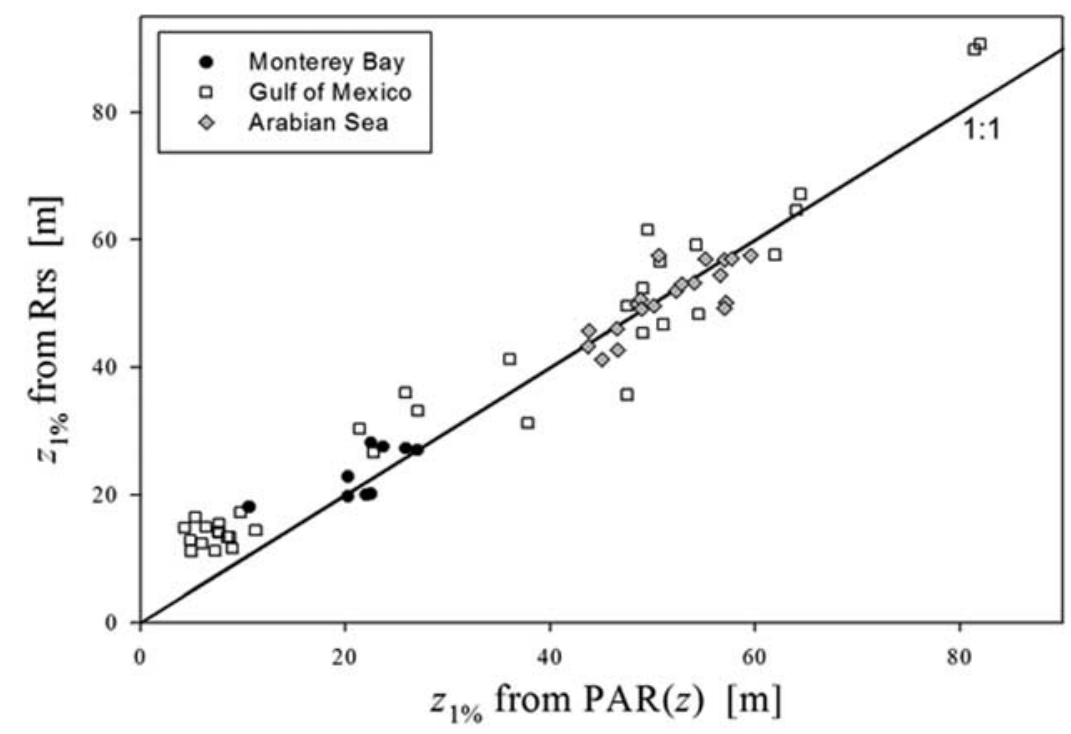

Figure 3. Comparison between $z_{1 \%}$ from [Chl]-centered approach and $z_{1 \%}$ from in situ PAR profile. $z_{1 \%}$ is calculated by equation (10), and all waters are assumed Case-1.

age coefficient of variation is $23 \%$ (maximum is $91 \%$ ). These values indicate varying optical or biological properties in the upper water column for each station. The excellent results of remotely estimated $z_{1 \%}$ and $z_{10 \%}$ apparently indicate that IOPs from the semianalytical algorithm and the analytical $K_{V I S}$ model integrate and largely compensate for some of the vertical variations. At least in part, this is because remote-sensing reflectance is always a measure of the weighted average of optical properties in the upper water column [Gordon and Clark, 1980; Sathyendranath and Platt, 1989; Zaneveld et al., 2005].

[27] It is important to recognize that what was carried out here were not regressions from the data set to develop an empirical relationship, but rather were independent tests of a system developed earlier from other sources. Such efforts, together with the resultant small error, provide us much higher confidence in the application of such semianalytically based approaches to broader ranges of environments. Additionally, there is no requirement of the waters to be Case-1 for the application of this IOP-centered approach, thereby avoiding the hurdle of identifying a water body as Case-1 or not [Lee and Hu, 2006; Mobley et al., 2004] before processing the data. The advantage of this IOPcentered approach is further supported by comparing the $z_{1 \%}$ values that are calculated from $R_{\mathrm{rs}}$-derived chlorophyll concentrations (see Figure 3 and below).

\section{2. [Chl]-Centered Approach}

[28] Figure 3 shows $z_{1 \%}$ derived from $R_{\mathrm{rs}}$ compared with measured $z_{1 \%}$ from $\operatorname{PAR}(z)$ for the same data set, but this time the concentration of chlorophyll-a is derived first empirically from $R_{\mathrm{rs}}$, and with the assumption that the waters under study fits the Case-1 category (equations (10) and (11)). The averaged error for $z_{1 \%}$ using this approach is $32.7 \%$ (maximum error is $218 \%$ ), whereas the average error of OC4v4 derived surface chlorophyll (Figure 4) is $75.2 \%$ with a maximum of $565 \%$. Generally, the derived $z_{1 \%}$ from $R_{\mathrm{rs}}[\mathrm{Chl}]$ matched the measured values better for waters with $z_{1 \%}$ deeper than $\sim 30 \mathrm{~m}$ (see Figure 3), but overestimated $z_{1 \%}$ for depths shallower than $\sim 30 \mathrm{~m}$. This might be because waters with deeper $z_{1 \%}$ are clearer, providing a better fit to the Case-1 assumption, although oceanic waters are not necessarily Case-1 [Lee and Hu, 2006; Mobley et al., 2004]. Waters with shallower $z_{1 \%}$ were often in coastal regions, and their optical properties were less likely to co-vary with chlorophyll concentration. This is also consistent with an earlier study regarding the downwelling diffuse attenuation coefficient [Lee et al., 2005a], where its value was underestimated (also based on $R_{\mathrm{rs}}$-derived [Chl]) for higher values (shallower $z_{1 \%}$ ), but was quite good for lower values (deeper $z_{1 \%}$ ). Compared with the $z_{1 \%}$ estimated from OC4v4-[Chl], $z_{1 \%}$ estimated from the IOP-centered approach are generally shallower and more consistent with measurements, which would lead to a smaller compensation irradiance if derived as in Siegel et al. [2002].

[29] It is necessary to emphasize that "the $z_{1 \%}$ relationship developed in Morel [1988] and Morel and Maritorena [2001] requires either the mean chlorophyll concentration or the water-column-integrated concentration - within the euphotic zone as input" (S. Maritorena, personal communication). Because of the existence of subsurface maxima of chlorophyll concentration, the mean value is normally greater than the surface value. Consequently, if surface chlorophyll (e.g., the product from current ocean-color

Table 1. Properties and Their Error Characters When Derived From Ocean-Color Remote Sensing

\begin{tabular}{|c|c|c|c|c|c|}
\hline & \multicolumn{3}{|c|}{ IOP-Centered Approach } & \multicolumn{2}{|c|}{$\begin{array}{l}\text { Chl-Centered } \\
\text { Approach }\end{array}$} \\
\hline & $z_{50 \%}$ & $z_{10 \%}$ & $z_{1 \%}$ & $z_{1 \%}$ & {$[\mathrm{Chl}]$} \\
\hline$\varepsilon$ (average error) & $18.5 \%$ & $13.8 \%$ & $13.7 \%$ & $32.7 \%$ & $75.2 \%$ \\
\hline Max. error & $70.9 \%$ & $61.2 \%$ & $63.5 \%$ & $218 \%$ & $565 \%$ \\
\hline RMSE & 0.117 & 0.077 & 0.079 & 0.162 & 0.329 \\
\hline
\end{tabular}




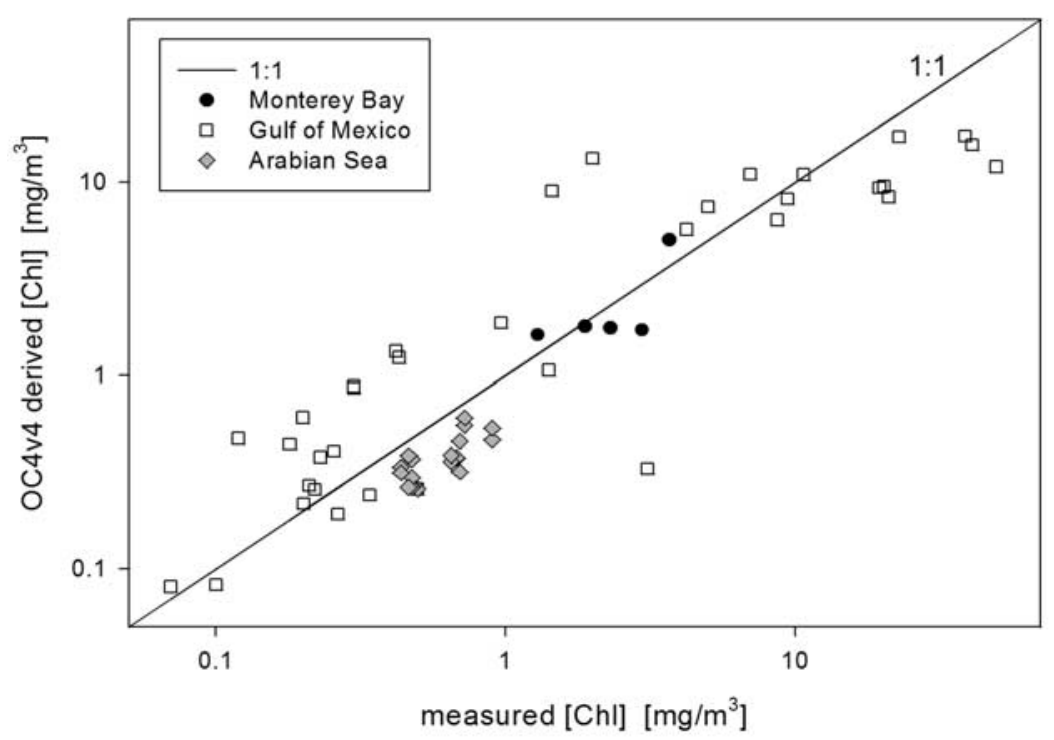

Figure 4. Comparison between $\mathrm{OC} 4 \mathrm{v} 4$ derived $[\mathrm{Chl}]$ and measured $[\mathrm{Chl}]$ from surface samples.

remote-sensing algorithms) is used for the calculation of $z_{1 \%}$, it is very likely that significant overestimation of $z_{1 \%}$ values will result, as shown by Figure 5 . Here $z_{1 \%}$ is calculated simply using the relationship developed in Morel and Maritorena [2001]. Since we do not always know the details of the vertical distribution of chlorophyll concentration for each station (especially from remote sensing), it is assumed arbitrarily that the mean concentration of chlorophyll within the euphotic zone is 1.3 times that derived by the OC4v4 algorithm. With this consideration, the average error for $z_{1 \%}$ is $34.3 \%$. The average error is much larger $(\varepsilon=$ $49.9 \%$ ) when no such adjustment is considered, but can be reduced to $22.3 \%$ if the mean concentration is assumed as 1.8 times the OC4v4 derived surface value.

\section{Conclusions and Implication to Ocean-Color Remote Sensing}

[30] In this study, euphotic zone depths (and two other environmental-optics depths) were derived semianalytically from spectral remote-sensing reflectance for measurements made in the Arabian Sea, the Gulf of Mexico, and the Monterey Bay. The derived values were then compared with the values from in-water vertical profiles of PAR. It was

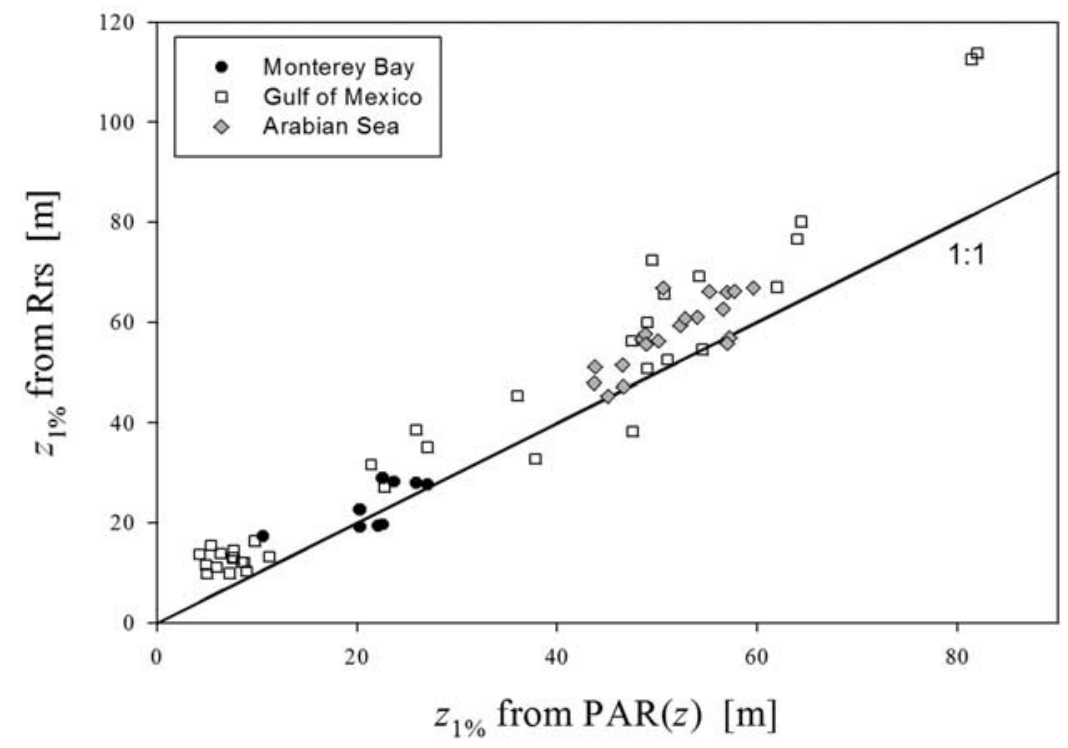

Figure 5. Comparison between $z_{1 \%}$ from [Chl]-centered approach and $z_{1 \%}$ from in situ PAR profile. Here $z_{1 \%}$ is calculated by rearranging equation (6) of Morel and Maritorena [2001], and the average [Chl] in the euphotic zone is assumed as 1.3 times the surface value derived by OC4v4 (see text for details). 
found that the two agreed with each other very well for the entire range of the data set. The average percentage error in linear scale is $18.5 \%$ for $z_{50 \%}$ (in a range of $0.6-18.0 \mathrm{~m}$ ), $13.8 \%$ for $z_{10 \%}(2.1-47.1 \mathrm{~m})$, and $13.7 \%$ for $z_{1 \%}(4.3-$ $82.0 \mathrm{~m})$. Such small errors suggest a closure between the two independent measurements and determinations, and indirectly validate the semianalytical derivation of IOPs from $R_{\mathrm{rs}}$ and the IOP-centered model of $K_{\mathrm{VIS}}$. To ensure its reliable applications to broad range of waters, however, more tests and validations with a wider dynamic range are certainly desired, especially for waters with $z_{1 \%}$ deeper than $100 \mathrm{~m}$.

[31] Also presented are comparisons of $z_{1 \%}$ calculated from the same $R_{\mathrm{rs}}$ but based on a methodology that uses chlorophyll values and the Case- 1 water assumption. The average error is much larger (32.7\%) when compared with $z_{1 \%}$ from measurements, with better results for oceanic waters, but overestimates $z_{1 \%}$ for coastal waters. As discussed earlier, the primary source contributing to this larger error includes the inclusion of coastal waters with many stations hardly belonging to the Case-1 category. An average error of $75 \%$ in [Chl] determined by the OC4v4 algorithm for these waters suggests that use of a global algorithm for coastal waters imparts a significant contribution to the error field.

[32] The IOP-centered approach, however, worked not only with oceanic waters, but also with the more complex coastal and shelf waters, as represented by the data collected in this study. Also, because the relationships between $z_{x \%}$ and $R_{\mathrm{rs}}$ are linked analytically by IOPs, this IOP-centered approach avoids parameterizations regarding the wide regional and seasonal bio-optical variations. This is extremely important if an algorithm is going to be applied to get quantitative global observations. In the current process of deriving [Chl] of global oceans from satellite ocean-color remote sensing, the "global" algorithm is with a single set of parameters that does not correct for regional and seasonal bio-optical variations when applied to global oceans. If proper regional and seasonal parameterizations are utilized as desired [Carder et al., 1989; O'Reilly et al., 1998], a different global mean value for chlorophyll, and, likely, a different temporal trend of this mean relative to those of Gregg and Conkright [2002] and Antoine et al. [2005], would be reached (Shang and Lee, manuscript in preparation, 2007).

[33] Euphotic zone depth $\left(z_{1 \%}\right)$ (or 10\%-light depth, $z_{10 \%}$ ) represents depths where only $1 \%$ (or $10 \%$ ) of surface PAR remains. Compared with the measurement of chlorophyll concentration (large uncertainties exist between measured by HPLC method and measured by fluorometric method [Mueller et al., 2002b; Trees et al., 1985]), or measurement of absorption and scattering coefficients of the bulk water or phytoplankton, $z_{1 \%}$ (or $z_{10 \%}$ ) is much easier and more accurate to determine in the field. It does not require an absolute radiometric calibration of the PAR sensor, and it does not require delicate calibration of the final product or complicated and commonly error-bearing post processing (e.g., the absorption coefficient of phytoplankton from filter-pad technique [Allali et al., 1995; Cleveland and Weidemann, 1993; Mitchell, 1990]).

[34] Also, the close agreement between $R_{\mathrm{rs}}$-calculated and field-measured $z_{1 \%}\left(\right.$ and $\left.z_{10 \%}\right)$ can, in large part, be attrib- uted to the fact that both are cumulative measurements of the upper water column. Chlorophyll concentrations or absorption and backscattering coefficients from discrete water samples may not accurately represent the average of the upper water column unless it is uniform; and, consequently, larger uncertainty will be introduced when comparing the values from discrete water samples with those from remote sensing. Many of those uncertainties would be minimized for $z_{1 \%}$ (or $z_{10 \%}$ ), and we can safely set an accuracy goal of within $20 \%$ from satellite measurements after further evaluation and refinement. Remote-sensing products with such a small error will bring confidence on quantitative ocean-color remote sensing and boost interests and applications of professionals and the general public.

[35] Because of these distinctive and unique characteristics, and because the error of measured $z_{1 \%}$ is significantly smaller than that of chlorophyll-a concentration, $z_{1 \%}$ (and/or $z_{10 \%}$ ) can be an ideal parameter to validate a system of ocean-color remote sensing. More importantly, $z_{1 \%}\left(\right.$ or $\left.z_{10 \%}\right)$ measures water clarity much more rigorously than Secchi depth [Preisendorfer, 1986] and provides much more reliable results. The variations of $z_{1 \%}$ (or $z_{10 \%}$ ) (after removing sun angle effects) indicate clearly changes of water quality of an ecosystem. A time series of $z_{1 \%}\left(\right.$ or $\left.z_{10 \%}\right)$ of the global oceans from satellite measurements, combined with historical and new measurements, will provide us unprecedented and confident evaluation of the distribution and trend of water clarity of the world oceans. Note that water clarity has profound effects on primary production [Behrenfeld and Falkowski, 1997; Platt and Sathyendranath, 1988] and heat deposition [Kirk, 1988; Lewis et al., 1990; Morel and Antoine, 1994; Zaneveld et al., 1981] in the upper water column.

\section{Appendix A: Updated Quasi-Analytical Algorithm (QAA_v4)}

[36] The Quasi-Analytical Algorithm (QAA) was developed by Lee et al. [2002] to derive the absorption and backscattering coefficients by inverting spectral remotesensing reflectance $\left(R_{\mathrm{rs}}(\lambda)\right)$. QAA starts with the calculation of the total absorption coefficient $(a)$ at a reference wavelength $\left(\lambda_{0}\right)$, and then propagate the calculation to other wavelengths. To briefly summarize, this algorithm consists of the following elements:

[37] 1. The ratio of backscattering coefficient $\left(b_{\mathrm{b}}\right)$ to the sum of backscattering and absorption coefficients $\left(b_{\mathrm{b}} /(a+\right.$ $\left.\left.b_{\mathrm{b}}\right)\right)$ at $\lambda$ is calculated algebraically based on the models of Gordon et al. [1988] and Lee et al. [1999],

$$
\frac{b_{b}(\lambda)}{a(\lambda)+b_{b}(\lambda)}=\frac{-0.0895+\sqrt{0.008+0.499 r_{r s}(\lambda)}}{0.249} .
$$

Here $r_{\mathrm{rs}}(\lambda)$ is the spectral remote-sensing reflectance just below the surface and is calculated from $R_{r s}(\lambda)$ through,

$$
r_{r s}(\lambda)=R_{r s}(\lambda)\left(0.52+1.7 R_{r s}(\lambda)\right) .
$$



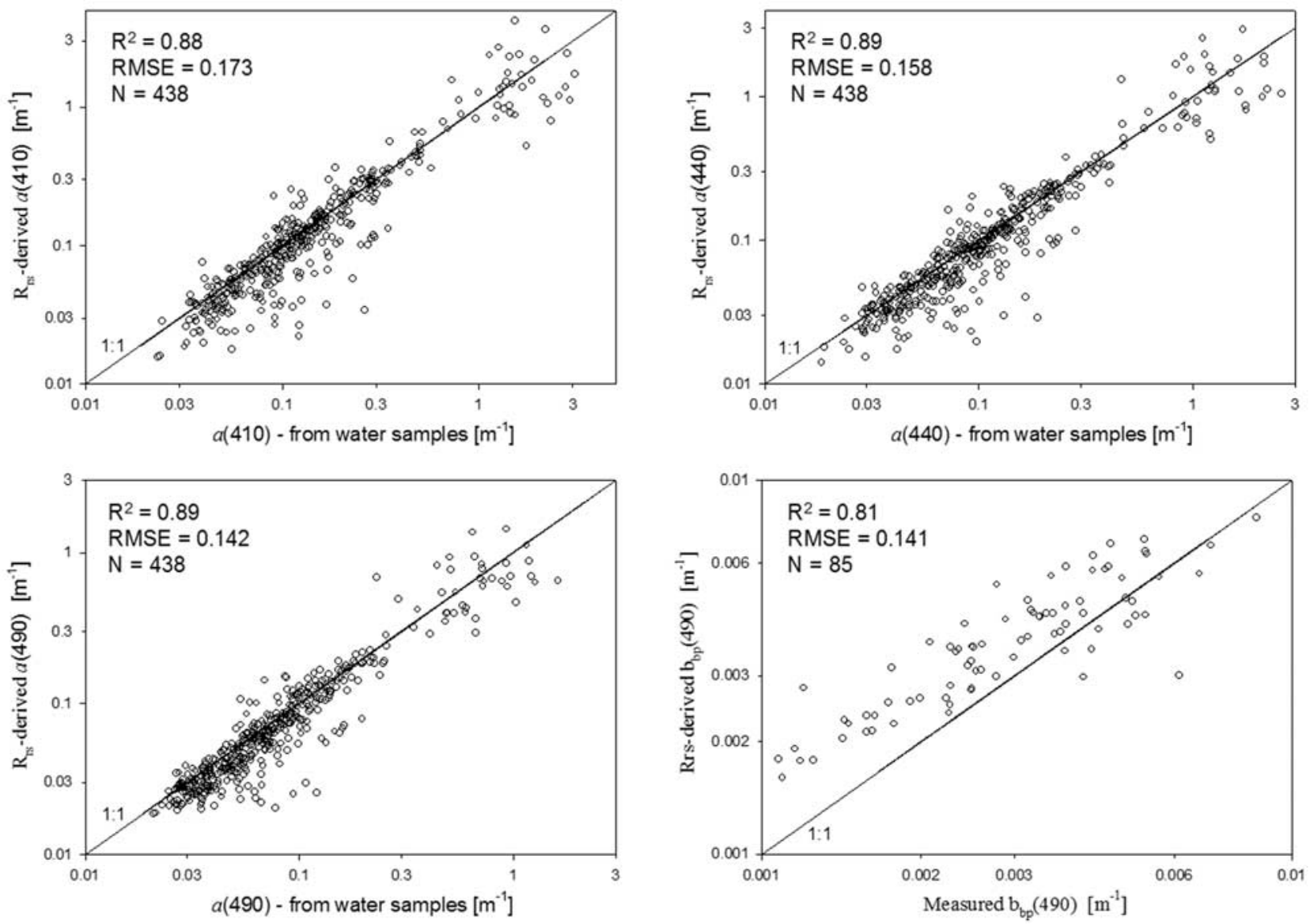

Figure A1. Comparison between IOPs derived from $R_{\mathrm{rs}}$ and IOPs from in situ measurements. QAA_v4 was used for the derivation of IOPs, and $R_{\mathrm{rs}}$ values at $410,440,490,555$, and $670 \mathrm{~nm}$ were used as inputs.

[38] 2. The spectral $b_{\mathrm{b}}(\lambda)$ is modeled with the widely used expression [Gordon and Morel, 1983; Smith and Baker, 1981],

$$
b_{b}(\lambda)=b_{b w}(\lambda)+b_{b p}\left(\lambda_{0}\right)\left(\frac{\lambda_{0}}{\lambda}\right)^{\eta}
$$

where $b_{\mathrm{bw}}$ and $b_{\mathrm{bp}}$ are the backscattering coefficients of pure seawater and suspended particles, respectively. Values of $b_{\mathrm{bw}}(\lambda)$ are provided in Morel [1974].

[39] 3. When $a\left(\lambda_{0}\right)$, the ratio of $b_{\mathrm{b}} /\left(a+b_{\mathrm{b}}\right)$ at $\lambda_{0}$, and $b_{\mathrm{bw}}\left(\lambda_{0}\right)$ are known, $b_{\mathrm{bp}}\left(\lambda_{0}\right)$ in equation (A3) can be easily derived with the combination of equations (A1) and (A3). The values of $b_{\mathrm{bp}}(\lambda)$ at other wavelengths are then calculated after the power parameter $(\eta)$ is estimated from [Lee et al., 2002],

$$
\eta=2.2\left(1-1.2 \exp \left(-0.9 \frac{r_{r s}(440)}{r_{r s}(555)}\right)\right) .
$$

[40] 4. Finally, by applying $b_{\mathrm{b}}(\lambda)$ to the ratio of $b_{\mathrm{b}} /(a+$ $b_{\mathrm{b}}$ ) at $\lambda$ (equation (A1)), the total absorption coefficient at $\lambda$, $a(\lambda)$, is calculated algebraically.
[41] The update of the QAA is related to the calculation of $a\left(\lambda_{0}\right)$. In this updated version of QAA (v.4), it has two selections for the calculation of $a(555)$ : one for data sets where there are no $R_{\mathrm{rS}}$ measurements at longer wavelengths (640 or $670 \mathrm{~nm}$, for instance); and one for data sets where there are $R_{\mathrm{rs}}$ measurements at those longer wavelengths. And the second round of calculation [Lee et al., 2002] is removed.

[42] For data sets having no $R_{\mathrm{rs}}$ at longer wavelengths, $a(555)$ is now estimated using the ratio $\rho=$ $\log \left(\max \left(R_{r s}(440,490,510)\right) / R_{r s}(555)\right)$ (for use with the SeaWiFS sensor), and takes the form,

$$
K(555)=0.0605+10^{-1.163-1.969 \rho+1.239 \rho^{2}+0.417 \rho^{3}-0.984 \rho^{4}},
$$

$$
a(555)=\frac{0.9 K(555)\left(1-6.8 R_{r s}(555)\right)}{1+15.3 R_{r s}(555)} .
$$

[43] The constants in equations (A5) and (A6) are combinations of those from OC4v4 [O'Reilly et al., 2000] and Morel and Maritorena [2001].

[44] For data sets having $R_{\mathrm{rs}}$ at $640 \mathrm{~nm}$ (note that $R_{\mathrm{rs}}$ at longer wavelengths are very important for inversion of 
waters with high absorption coefficients [IOCCG, 2006; Lee et al., 2005a]), a(555) is now estimated as follows,

$$
\begin{gathered}
\chi=\log \left(\frac{R_{r s}(440)+R_{r s}(490)}{R_{r s}(555)+2 \frac{R_{r s}(640)}{R_{r s}(490)} R_{r s}(640)}\right), \\
a(555)=a_{w}(555)+10^{-1.226-1.214 \chi-0.350 \chi^{2}},
\end{gathered}
$$

with constants in equation (A8) obtained by least squares fitting $a(555)$ of the synthetic data set adopted by the IOCCG [IOCCG, 2006].

[45] In the original version of QAA [Lee et al., 2002] a relatively arbitrary boundary was used for the transition between values calculated with $555 \mathrm{~nm}$ and $640 \mathrm{~nm}$ as reference wavelengths, respectively. In this updated QAA (equations (A7) and (A8)), now seamless transition is achieved for waters from open ocean to coastal region. Available measurements suggest that QAA_v4 is applicable to waters with $a(440)$ as high as $\sim 2.0 \mathrm{~m}^{-1}$. Simply change the corresponding values at $555 \mathrm{~nm}$ to that at $550 \mathrm{~nm}$, QAA_v4 (equations (A7) and (A8)) can be applied to data from $\bar{b}$ oth SeaWiFS and MODIS without significant effects to the final results.

[46] For the SeaWiFS and MODIS sensor, there is no band to measure $R_{\mathrm{rs}}$ at $640 \mathrm{~nm}$, but there are bands to measure $R_{\mathrm{rs}}$ at 667 and/or $678 \mathrm{~nm}$. For such cases, a simulated $R_{\mathrm{rs}}(640)$ needs to be generated as in Lee et al. [2005a], which is

$$
\begin{aligned}
R_{r s}(640) & =0.01 R_{r s}(555)+1.4 R_{r s}(667) \\
& -0.0005 R_{r s}(667) / R_{r s}(490)
\end{aligned}
$$

and this simulated $R_{\mathrm{rs}}(640)$ is kept greater than $1.2 R_{\mathrm{rs}}(667)$.

[47] Figure A1 compares optical properties derived from $R_{\mathrm{rs}}$ by QAA_v4 $(a(555)$ from equation (A8)) with that from water-sample measurements, where data is from the NOMAD OCBAM data set [Werdell and Bailey, 2005], but subsampled for valid measurements of both $R_{\mathrm{rs}}$ and IOPs (T. Smyth, personal communication). Clearly, excellent agreements were achieved between the two independent determinations. To indicate the applicability of QAA_v4 with satellite data, it was the simulated $R_{\mathrm{rs}}(640)$ (equation (A9)) instead of the measured $R_{\mathrm{rs}}(640)$ used in the derivation of IOPs (and the $z_{x \%}$ ) in this study.

[48] For a recent measurement made in the south Pacific gyre (M. Lewis, personal communication), consistent results (with $z 1 \%$ around $150 \mathrm{~m}$ ) were obtained from measurements of the vertical profiles and the remote sensing reflectance.

[49] Acknowledgments. We thank Tom Peacock, Joseph Rhea, and Jim Mueller for helping with the data collection. Comments and suggestions from Grace Chang and Emmanuel Boss are greatly appreciated. Financial support was provided by NASA through grant NNH06AE55I, and NRL through the 6.1 project "Physical-Biological-Optical Modeling of the Coastal Environment" funded by the Office of Naval Research under Program Element 61153N and 6.2 Project "Tactical UAV hyperspectral imagery for riverine special operations" under Program Element $0602435 \mathrm{~N}$. Funding was also provided to USF through ONR contract N00014-02-1-0211 and NASA grant NNG04GL55G.

\section{References}

Allali, K., A. Bricaud, M. Babin, A. Morel, and P. Chang (1995), A new method for measuring spectral absorption coefficients of marine particles, Limnol. Oceanogr., 40, 1526-1532.

Antoine, D., A. Morel, H. R. Gordon, V. F. Banzon, and R. H. Evans (2005), Bridging ocean color observations of the 1980s and 2000s in search of long-term trends, J. Geophys. Res., 110, C06009, doi:10.1029/2004JC002620.

Behrenfeld, M. J., and P. G. Falkowski (1997), A consumer's guide to phytoplankton primary productivity models, Limnol. Oceanogr., 42(7), $1479-1491$.

Behrenfeld, M. J., E. Boss, D. Siegel, and D. M. Shea (2005), Carbon-based ocean productivity and phytoplankton physiology from space, Global Biogeochem. Cycles, 19, GB1006, doi:10.1029/2004GB002299.

Carder, K. L., and R. G. Steward (1985), A remote-sensing reflectance model of a red tide dinoflagellate off West Florida, Limnol. Oceanogr. 30, 286-298.

Carder, K. L., R. G. Steward, G. R. Harvey, and P. B. Ortner (1989), Marine humic and fulvic acids: their effects on remote sensing of ocean chlorophyll, Limnol. Oceanogr., 34, 68-81.

Chang, G. C., and T. D. Dickey (2004), Coastal ocean optical influences on solar transmission and radiant heating rate, J. Geophys. Res., 109, C01020, doi:10.1029/2003JC001821.

Cleveland, J. S., and A. D. Weidemann (1993), Quantifying absorption by aquatic particles: A multiple scattering correction for glass-fiber filters, Limnol. Oceanogr., 38, 1321-1327.

Gordon, H. R. (1985), Ship perturbation of irradiance measurements at sea, 1: Monte Carlo simulations, Appl. Opt., 24, 4172-4182.

Gordon, H. R., and D. K. Clark (1980), Remote sensing optical properties of a stratified ocean: an improved interpretation, Appl. Opt., 19, 34283430 .

Gordon, H. R., and A. Morel (1983), Remote Assessment of Ocean Color for Interpretation of Satellite Visible Imagery: A Review, 44 pp., Springer, New York.

Gordon, H. R., O. B. Brown, R. H. Evans, J. W. Brown, R. C. Smith, K. S. Baker, and D. K. Clark (1988), A semianalytic radiance model of ocean color, J. Geophys. Res., 93, 10,909-10,924.

Gregg, W. W., and M. E. Conkright (2002), Decadal changes in global ocean chlorophyll, Geophys. Res. Lett., 29(15), 1730, doi:10.1029/ 2002GL014689.

IOCCG (2000), Remote sensing of ocean colour in coastal, and other optically-complex, waters, in Reports of the International Ocean-Colour Coordinating Group, vol. 3, edited by S. Sathyendranath, Dartmouth, Canada. IOCCG (2006), Remote sensing of inherent optical properties: Fundamentals, tests of algorithms, and applications, in Reports of the International Ocean-Colour Coordinating Group, vol. 5, edited by Z.-P. Lee, 135 pp., Dartmouth, Canada.

Kara, A. B., A. J. Wallcraft, and H. E. Hurlburt (2005), Sea Surface Temperature sensitivity to water turbidity from simulations of the turbid Black Sea using HYCOM, J. Phys. Oceanogr., 35, 33-54.

Kirk, J. T. O. (1988), Solar heating of water bodies as influenced by their inherent optical properties, J. Geophys. Res., 93(D9), 10,897-10,908.

Kirk, J. T. O. (1994), Light and Photosynthesis in Aquatic Ecosystems, Cambridge Univ. Press, New York.

Lee, Z. P., and C. Hu (2006), Global distribution of Case-1 waters: An analysis from SeaWiFS measurements, Remote Sens. Environ., 101, $270-276$.

Lee, Z. P., K. L. Carder, C. D. Mobley, R. G. Steward, and J. S. Patch (1999), Hyperspectral remote sensing for shallow waters: 2. Deriving bottom depths and water properties by optimization, Appl. Opt., 38, $3831-3843$

Lee, Z. P., K. L. Carder, and R. Arnone (2002), Deriving inherent optical properties from water color: A multi-band quasi-analytical algorithm for optically deep waters, Appl. Opt., 41, 5755-5772.

Lee, Z. P., M. Darecki, K. L. Carder, C. Davis, D. Stramski, and W. J. Rhea (2005a), Diffuse attenuation coefficient of downwelling irradiance: An evaluation of remote sensing methods, J. Geophys. Res., 110, C02017, doi:10.1029/2004JC002573.

Lee, Z. P., K. Du, R. Arnone, S. C. Liew, and B. Penta (2005b), Penetration of solar radiation in the upper ocean: A numerical model for oceanic and coastal waters, J. Geophys. Res., 110, C09019, doi:10.1029/ 2004JC002780.

Lewis, M. R., M. Carr, G. Feldman, W. Esaias, and C. McMclain (1990), Influence of Penetrating solar radiation on the heat budget of the equatorial Pacific Ocean, Nature, 347, 543-545.

Liu, C.-C., K. L. Carder, R. L. Miller, and J. E. Ivey (2002), Fast and accurate model of underwater scalar irradiance, Appl. Opt., 41, $4962-4974$.

Liu, C.-C., R. L. Miller, K. L. Carder, Z. P. Lee, E. J. D'Sa, J. E. Ivey, and I.-I. Lin (2006), Estimating the underwater light field from remote sensing of ocean color, J. Oceanogr., 62, 235-248. 
Mitchell, B. G. (1990), Algorithms for determining the absorption coefficient for aquatic particles using the quantitative filter technique, in Ocean Optics X, pp. 137-148, SPIE-The Int. Soc. for Opt. Eng., Bellingham, Wash.

Mobley, C. D. (1995), Hydrolight 3.0 Users' Guide, SRI Int., Menlo Park, Calif.

Mobley, C. D., D. Stramski, W. P. Bissett, and E. Boss (2004), Optical modeling of ocean waters: Is the Case 1 - Case 2 classification still useful?, Oceanography, 17(2), 60-67.

Morel, A. (1974), Optical properties of pure water and pure sea water, in Optical Aspects of Oceanography, edited by N. G. Jerlov and E. S. Nielsen, pp. 1-24, Elsevier, New York.

Morel, A. (1988), Optical modeling of the upper ocean in relation to its biogenous matter content (Case I waters), J. Geophys. Res., 93, 10,74910,768 .

Morel, A., and D. Antoine (1994), Heating rate within the upper ocean in relation to its bio-optical state, J. Phys. Oceanogr., 24, 1652-1665.

Morel, A., and J. F. Berthon (1989), Surface pigments, algal biomass profiles, and potential production of the euphotic layer: relationships reinvestigated in review of remote-sensing applications, Limnol. Oceanogr., $34,1545-1562$.

Morel, A., and B. Gentili (2004), Radiation transport within oceanic (case 1) water, J. Geophys. Res., 109, C06008, doi:10.1029/2003JC002259.

Morel, A., and S. Maritorena (2001), Bio-optical properties of oceanic waters: A reappraisal, J. Geophys. Res., 106, 7163-7180.

Morel, A., and L. Prieur (1977), Analysis of variations in ocean color, Limnol. Oceanogr., 22, 709-722.

Mueller, J. L., and R. E. Lange (1989), Bio-optical provinces of the northeast Pacific Ocean: a provisional analysis, Limnol. Oceanogr., 34, $1572-$ 1586.

Mueller, J. L., C. Davis, R. Arnone, R. Frouin, K. L. Carder, Z. P. Lee, R. G. Steward, S. Hooker, C. D. Mobley, and S. McLean (2002a), Above-water radiance and remote sensing reflectance measurement and analysis protocols, in Ocean Optics Protocols for Satellite Ocean Color Sensor Validation, Revision 3, edited by J. L. Mueller and G. S. Fargion, NASA Tech. Memo., TM-2002-210004, 171-182.

Mueller, J. L., et al. (2002b), Ocean optics protocols for satellite ocean color sensor validation, Revision 3, Part II, NASA Tech. Memo., TM-2002210004, 178-308.

Ohlmann, J. C., and D. Siegel (2000), Ocean radiant heating. Part II: Parameterizing solar radiation transmission through the upper ocean, J. Phys. Oceanogr., 30, 1849-1865.

O'Reilly, J., S. Maritorena, B. G. Mitchell, D. Siegel, K. L. Carder, S. Garver, M. Kahru, and C. McClain (1998), Ocean color chlorophyl algorithms for SeaWiFS, J. Geophys. Res., 103, 24,937-24,953.

O'Reilly, J., et al. (2000), Postlaunch calibration and validation analyses, Part 3, NASA technical memorandum, edited by S. B. Hooker and E. R. Firestone, NASA Goddard Space Flight Cent., Greenbelt, Md.

Paulson, C. A., and J. J. Simpson (1977), Irradiance measurements in the upper ocean, J. Phys. Oceanogr., 7, 953-956.

Platt, T., and S. Sathyendranath (1988), Oceanic primary production: estimation by remote sensing at local and regional scales, Science, 241, $1613-1620$.

Preisendorfer, R. W. (1976), Hydrologic Optics, vol. 1, Introduction, Natl. Tech. Inf. Serv., Springfield, Va.
Preisendorfer, R. W. (1986), Secchi disk science: Visual optics of natural waters, Limnol. Oceanogr., 31(5), 909-926.

Prieur, L., and S. Sathyendranath (1981), An optical classification of coastal and oceanic waters based on the specific spectral absorption curves of phytoplankton pigments, dissolved organic matter, and other particulate materials, Limnol. Oceanogr., 26, 671-689.

Sathyendranath, S., and T. Platt (1989), Remote sensing of ocean chlorophyll: consequence of nonuniform pigment profile, Appl. Opt., 28, 490495.

Sathyendranath, S., T. Platt, C. M. Caverhill, R. E. Warnock, and M. R. Lewis (1989a), Remote sensing of oceanic primary production: computations using a spectral model, Deep Sea Res., 36, 431-453.

Sathyendranath, S., L. Prieur, and A. Morel (1989b), A three-component model of ocean colour and its application to remote sensing of phytoplankton pigments in coastal waters, Int. J. Remote Sens., 10, $1373-$ 1394.

Sathyendranath, S., A. D. Gouveia, S. R. Shetye, P. Ravindran, and T. Platt (1991), Biological control of surface temperature in the Arabian Sea Nature, 349 (54-56)

Siegel, D. A., S. C. Doney, and J. A. Yoder (2002), The North Atlantic spring phytoplankton bloom and Sverdrup's critical depth hypothesis, Science, 296, 730-733.

Smith, R. C., and K. S. Baker (1981), Optical properties of the clearest natural waters, Appl. Opt., 20, 177-184.

Smith, R. C., C. R. Booth, and J. L. Star (1984), Oceanographic bio-optical profiling system, Appl. Opt., 23, 2791-2797.

Trees, C., M. C. Kennicutt, and J. M. Brooks (1985), Errors associated with the standard fluorometric determination of chlorophylls and phaeopigments, Mar. Chem., 17, 1-12.

Werdell, P. J., and S. W. Bailey (2005), An improved bio-optical data set for ocean color algorithm development and satellite data product validation, Remote Sens. Environ., 98, 122-140.

Zaneveld, J. R. V., and R. W. Spinrad (1980), An arc tangent model of irradiance in the sea, J. Geophys. Res., 85(C9), 4919-4922.

Zaneveld, J. R. V., J. C. Kitchen, and H. Pak (1981), Influence of optical water type on the heating rate of a constant depth mixed layer, J. Geophys. Res., 86, 6426-6428.

Zaneveld, J. R. V., J. C. Kitchen, and J. L. Mueller (1993), Vertical structure of productivity and its vertical integration as derived from remotely sensed observations, Limnol. Oceanogr., 38, 1384-1393.

Zaneveld, J. R. V., E. Boss, and A. Barnard (2001), Influence of surface waves on measured and modeled irradiance profiles, Appl. Opt., 40(9), $1442-1449$.

Zaneveld, J. R. V., A. H. Barnard, and E. Boss (2005), Theoretical derivation of the depth average of remotely sensed optical parameters, Opt. Express, 13, 9052-9061.

R. Arnone, J. Kindle, Z. Lee, and A. Weidemann, Naval Research Laboratory, Code 7330, Stennis Space Center, MS 39529, USA. (zplee@nrlssc.navy.mil)

K. L. Carder, College of Marine Science, University of South Florida, 1407 th Ave. S., St. Petersburg, FL 33701, USA.

C. Davis, College of Oceanic and Atmospheric Sciences, Oregon State University, 104 COAS Admin. Bldg., Corvallis, OR 97331, USA. 